\title{
A NEW HIGH STRENGTH GOLD BOND WIRE
}

\section{Giles Humpston \& David M. Jacobson,}

Hirst Research Centre,

GEC-Marconi Ltd.,

Wembley, Middlesex HA9 7PP

United Kingdom

As semiconductor technology develops, conventional

bond wires are reaching the limits of their capability.

Industry is demanding finer diameter wire coupled with higher strength, and the retention of this strength at elevated temperatures would be a decided advantage.

It has been demonstrated that a fine wire of the composition Au-1wt.\%Ti, which was originally formulated for high carat jewellery, can be endowed with these beneficial properties by

appropriate thermomechanical treatments. A three-fold increase in the strength of $25 \mu \mathrm{m}$ diameter wire over that of conventional gold wire has been achieved.

The mechanical properties are stable even when the wire is subjected to heating at $400{ }^{\circ} \mathrm{C}$ for over a year.

Wire based on the Au-1wt.\%Ti alloy can be made comparable to that of the standard gold products in terms of its electrical properties and bonding characteristics.

Moreover, it is more resilient to the demands of the fabrication process. 


\section{INTRODUCTION}

Electronic circuitry normally contains semiconductor chips, which are elaborate miniature circuits processed in thin slices of silicon or gallium arsenide, typically 1 to $500 \mathrm{~mm}^{2}$ in size. These semiconductor chips are housed in hermetic packages to protect them from moisture and mechanical damage. A ceramic package containing a chip, before attachment of the lid, is shown in Figure 1, Three main methods are used for making electrical connection between contact pads on the microchips and the external circuitry, namely wire bonding, tape automated bonding (TAB) and flip-chip bonding.

Wire bonding entails using fine wires, typically $33 \mu \mathrm{m}$ diameter or less, to connect the bond pads on semiconductor devices to the headers on their packages or to the tracks on circuit boards in hybrìd assem-

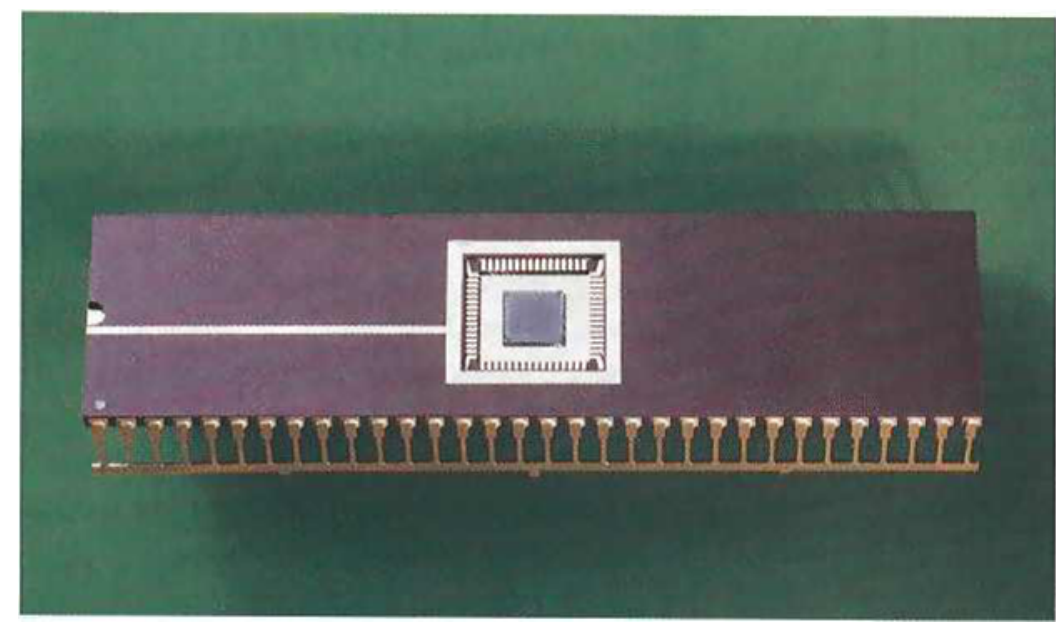

Figure 1

A silicon semiconductor chip soldered into a gold metallised recess in a ceramic package. This style of component is finished by connecting fine gold wires between contact pads on the chip and terminals in the package, and then soldering a lid on

blies. In this method, the bond pads on the devices and the headers on the packages or circuit boards are metallised with either gold or an aluminium alloy, depending on the intended application of the device. The ends of the fine wire interconnect are attached to the appropriate device pad and header by micro-welding. The sequence of steps involved in making an individual wire bond are illustrated schematîcally in Figure 2. A semiconductor chip connected to its package with gold bond wires is shown in Figure 3 .

In $\mathrm{TAB}$, the device is joined using a 'gang' bonding operation to a set of cantilever beams on a polymeric tape (inner lead bonding) and subsequently these beam leads are attached to the circuit board or package (outer lead bonding). In flip-chip bonding, the silicon chip is mounted face down and its bond pads are directly soldered to those of the substrate. Representative configurations for these two types of interconnection are shown in Figures 4, 5 and 6 (pages 135, 136), respectively.

The principal features of the three interconnection technologies referred to above are listed in Table 1 (page 137). Despite the apparent technical merits of the $T A B$ and flip-chip processes, the wire bonding method has the commercial advantages of low set-up costs and adaptability to changing component design.

The materials traditionally used for bond wire are gold, aluminium and occasionally copper, containing minor additions of other elements. This choïce has been determined by a diversity of requirements, not least of which is the ability to prepare essentially continuous lengths of wire in suitable diameters, which may be as little as $4 \mu \mathrm{m}$, by either drawing or extrusion. Gold has special merits as bond wire including good resistance to corrosion, hîgh electrical conductivity and the relative ease with which it can be bonded into position in an ambient environment by standard micro-welding techniques. For these reasons, more than $90 \%$ of the wire bonds produced each year are made with gold wire [1].

The versatility of wire bonding is likely to ensure that its use will continue and even grow for the foreseeable future [2]. Indeed, the consumption of fine gold wire by the electronics industry has increased by roughly $20 \%$ per annum since 1970 and, despite the fineness of the product and the minuteness of the quantity of gold used in an interconnect (typically $20 \mu \mathrm{g}$ ), sales of gold bond wire exceeded \$150 million in 1991 [3]. 
Figure 2

Schematic illustration of the sequence of steps involved in making a single interconnect using bond wire:

Step 1:

A spark or small flame is used to locally melt the end of the wire so as to form a spherical ball that is approximately twice the diameter of the wire

Step 2:

The ball is thermosonically welded to an aluminium metallised pad on the semiconductor

Step 3:

A loop of wire is formed as the bonding capillary moves across to the contact pad of the device package or circuit board

Step 4:

The wire is thermosonically welded to the gold metallised pad of the package

Step 5:

A sharp edge on the tool is used to cut the wire, leaving a length protruding from the capillary that is of the correct length to form the next ball
The value of fine bond wire is dominated by the manufacturing cost rather than the metal content. This is highlighted in Figure 7 (page 138), which shows the price mark-up of precious metal fine wire in relation to gold bullion. Gold wire of $25 \mu \mathrm{m}$ diameter commands a price that is roughly eight times the bullion price, but this factor rises to almost a hundred for $10 \mu \mathrm{m}$ diameter wire, reflecting the technical difficulties in fabricating such fine wire and the higher processing costs. This explains the relatively small price differential between gold, copper and aluminium wire despite the approximate 60,000:6:1 ratio of the value of the respective metals on a volume basis.

\section{LIMITATIONS OF EXISTING BOND WIRE MATERIALS}

The functional requirements of bond wire used in semiconductor manufacture are as follows:

a) High electrical conductivity

b) Ease of welding

c) Adequate strength to permit use in modern high-speed bonding machines

d) Retention of strength during the heating routines encountered through device packaging and use.

In order to meet these requirements, existing bond wires comprise alloys of gold, aluminium and copper that exploit solid solution strengthening and work hardening mechanisms to attain adequate mechanical properties. However, this approach is increasingly less able to meet the demand for finer diameter wires in order to achieve increased miniaturisation coupled with boosted rates of production, which means using faster mïcrowelding machines. Rapid manipulation of the wire imposes significant forces on it; modern automated bonding machines can form a wire loop with a bond at each end in less than 0.1 second. It is perhaps significant that, in recent years, 


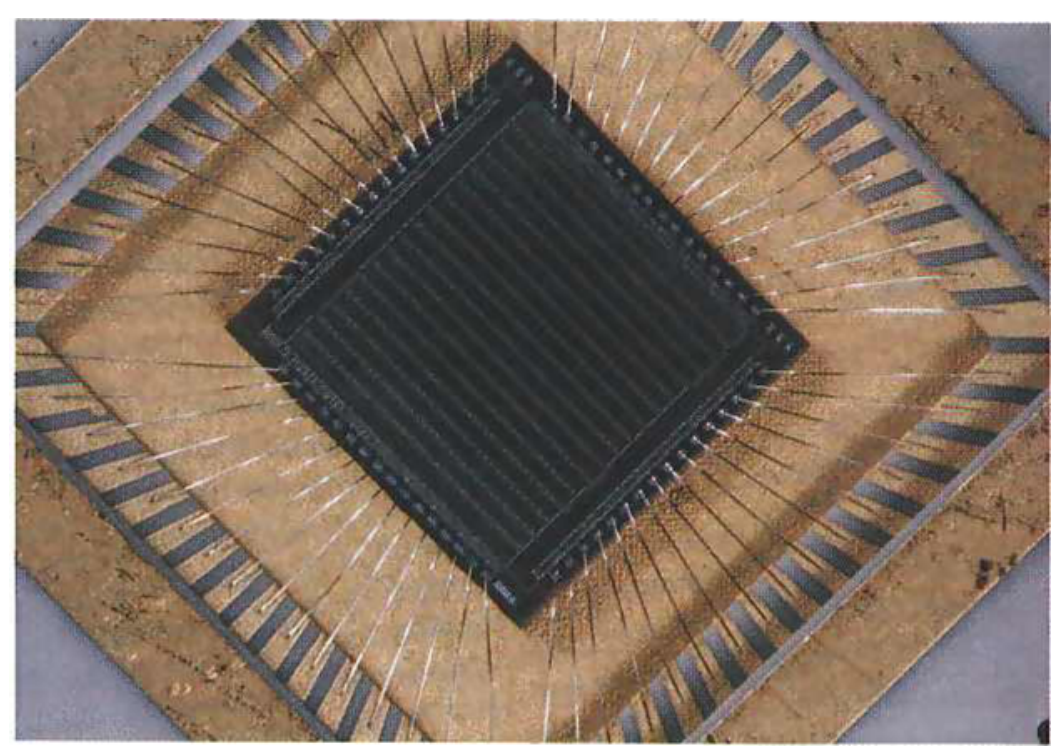

Figure 3

A close-up view of the gold bond wires of a silicon chip housed in a ceramic package

there has been a tendency to revert to $33 \mu \mathrm{m}$ diameter wire in place of $25 \mu \mathrm{m}$ gauge in order to cope with the high stresses imposed on the wire by modern bonding machines, notwithstanding the requirement for finer diameter wires consistent with higher interconnect densities.

Furthermore, ongoing progress in semiconductor technology means that the upper operating temperature of devices is being progressively raised which reduces the need for forced cooling with its associated space and cost penalties. Devices capable of continuous service at $300{ }^{\circ} \mathrm{C}$ are currently available and micron valves [4] are likely to be capable of operating in even harsher environments. Pure gold will anneal through recrystallisation and regrowth of the deformed grains at temperatures as low as $100^{\circ} \mathrm{C}$. When the grains grow to dimensions that are comparable to the diameter of the wire, the strength and fatigue properties of the wire greatly deteriorate.

The purpose of introducing solid solution strengthening elements is not only to improve the strength of the wire but, more particularly, to increase the recrys- tallisation temperature of the cold worked microstructure. By a judicious selection of the doping elements, it is possible to increase the recrystallisation temperature of gold bond wire up to a maximum of about $350{ }^{\circ} \mathrm{C}$ without significantly degrading its electrival characteristics [5], At first sight this might seem adequate but recrystallisation temperature is defined as 'the temperature at which recrystallisation is complete within one hour' This is an insufficiently demanding criterion for fine wire interconnects because the wire is often required to maintain its mechanical integrity over a long service life. The aluminium and copper alloys used for bond wire anneal at temperatures comparable to those for the gold alloys, so that all commercially available bond wire will soften progressively through the loss of its work-hardened microstructure and grain growth. A collation of data culled from the literature, presented in Figure 8 (page 139), shows that when exposed to temperatures above $300^{\circ} \mathrm{C}$, conventional gold alloys used for bond wire lose half of their strength in under one hour.

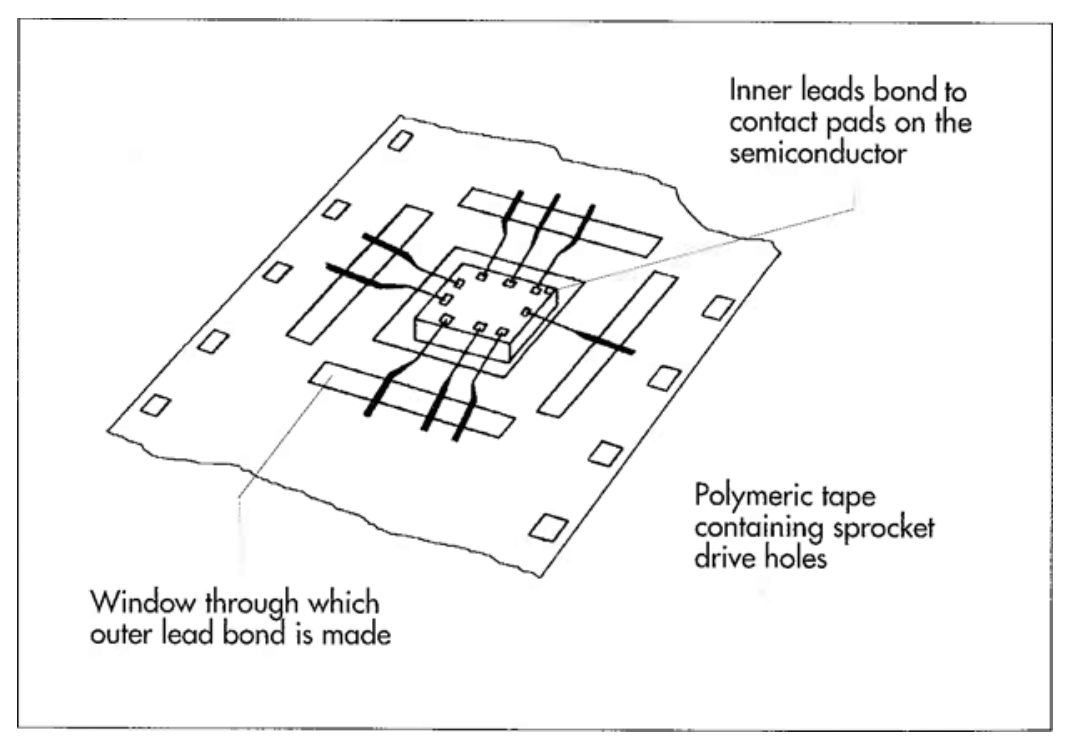

Figure 4

Schematic illustration of tape automated bonding (TAB): A semiconductor device with beam leads attached, beld on polymeric tape 


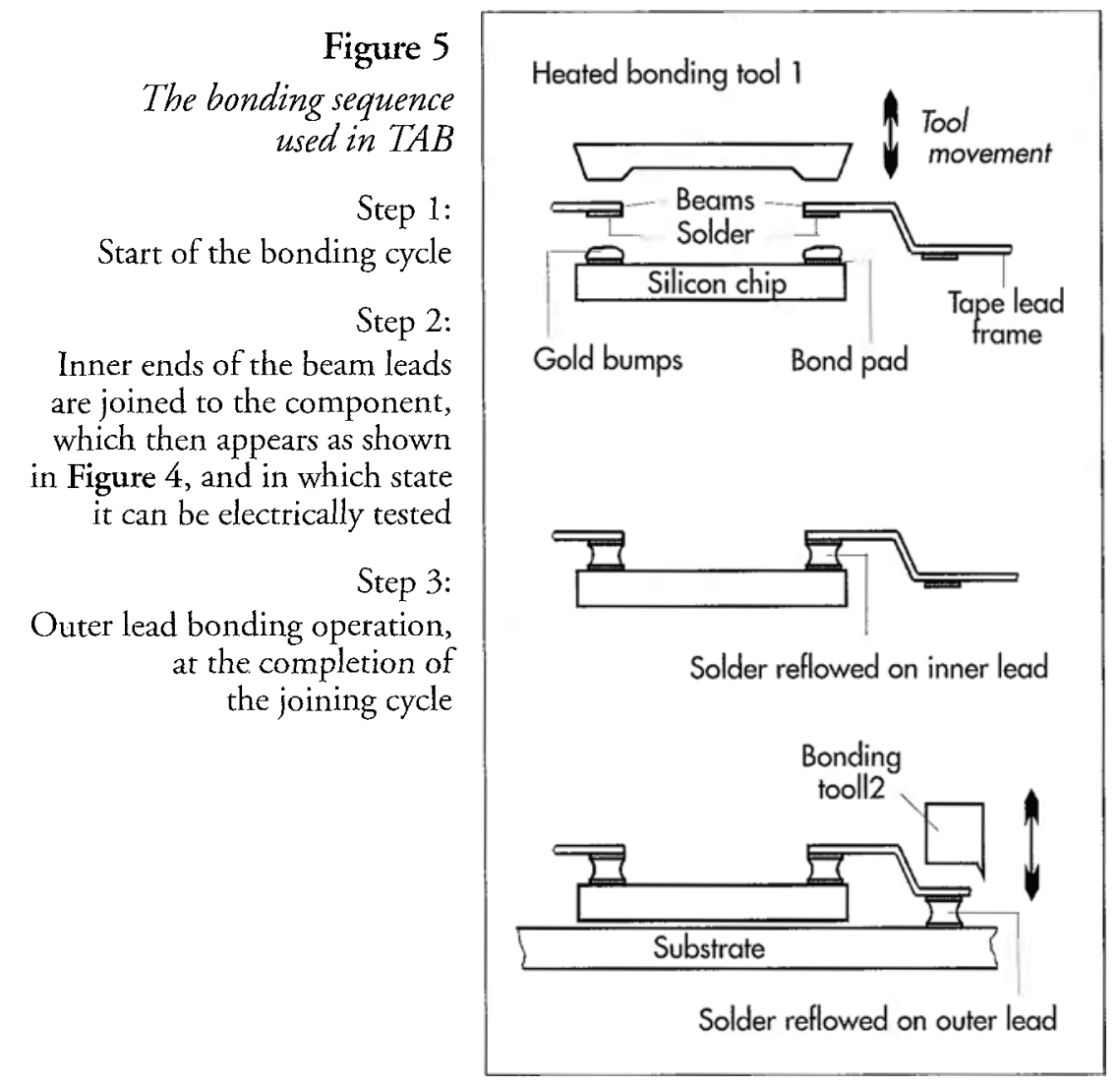

that possess electrical conductivities close to those of gold, copper and aluminium which are currently used in this application. The candidate materials must also be readily fabricated into fine wire, and be compatible with existing microwelding machines if they are to be adopted readily by the semiconductor industry. This article describes the development of a new gold alloy bond wire that is capable of meeting this set of requirements.

\section{REVIEW OF METALLURGICAL STRENGTHENING MECHANISMS}

Any enhancement in the resistance of bond wire to elevated temperatures can only be achieved by changing to new materials which can be strengthened by different mechanisms. The choice is limited to metals

As a first step towards developing a new high strength bond wire, it is necessary to select a material that is intrinsically strong, or can be strengthened, and which will retain the enhanced strength when exposed to elevated temperatures. Intrinsically strong metals that can be drawn to fine wire such as steel and tungsten are not amenable to micro-welding and have low electrical conductivity, so that attention focused instead on methods of strengthening gold.

Work hardening, achieved by mechanically deforming the metal so as to create dislocation tangles and other defects in the material, and solid solution strengthening, involving sub-percentage additions of a second constituent, are used in the existing range of bond wire metals. Strengthening of the wire by work harden- 
ing through cold drawing or extrusion operations is removed by relatively short, low temperature heat-treatments. On the other hand, solid solution strengthening is only capable of moderate improvements in mechanical properties.

More substantial improvements in strength can be achieved by introducing particles of a second phase into the host metal. There are three different ways in which this can be done. One is to create a fine dispersion of intermetallic precipitates in the metal to produce what is known as precipitation strengthening. In order to obtain the necessary fine dispersion of the second phase, the requisite alloy with a minor addition (typically 1 to $5 \mathrm{wt.} \%$ ) is prepared and homogenised at elevated temperature. It is then quench cooled to retain the minor constituent in solid solution at room temperature. This is followed by a second heat treatment at a lower temperature, where the solubility limit of the minor constituent is exceeded, so that a second phase will nucleate uniformly within the alloy. The particles of the second phase will steadily grow in size and decline in number if the heating is continued. There is an optimum particle size and density at which the strengthening effect is a maximum. Thereafter, the strength of the alloy will decline as the particles coarsen and their distribution density decreases.

The precipitation strengthening mechanism arises from the pinning of dislocations by the precipitate particles. To be effective at obstructing the movement of dislocations under the influence of an applied stress, the second phase particles need to be approximately $10 \mathrm{~nm}$ in diameter with a volumetric density greater that $10^{15}$ particles per $\mathrm{cm}^{3}$. The precipitation temperature must be high in relation to the temperature that the alloy will see in service or it will progressively weaken because there will be sufficient thermal activation for
Table 1

Comparison of semiconductor chip interconnection technologies, with representative data

\author{
with representaive dara
}

\begin{tabular}{|c|c|c|c|}
\hline Parameter & $\begin{array}{l}\text { Wire } \\
\text { bonding }\end{array}$ & $\begin{array}{c}\text { Tape } \\
\text { automated } \\
\text { bonding }\end{array}$ & $\begin{array}{l}\text { Flip chip } \\
\text { bonding }\end{array}$ \\
\hline Joining materials & $\begin{array}{l}\text { Gold or } \\
\text { aluminium } \\
\text { fine wire }\end{array}$ & $\begin{array}{l}\text { Copper beams } \\
\text { attached with } \\
\text { Au-20Sn solder }\end{array}$ & Pb-5Sn solder \\
\hline $\begin{array}{l}\text { Bond strength as made, } g \\
\text { After burn-in testing, } g\end{array}$ & $\begin{array}{l}10 \\
<2\end{array}$ & $\begin{array}{l}50 \\
50\end{array}$ & $\begin{array}{l}30 \\
20\end{array}$ \\
\hline $\begin{array}{l}\text { Number of } \\
\text { interconnects per mm }\end{array}$ & 5 & 10 & 5 \\
\hline per $\mathrm{mm}^{2}$ & 5 & 10 & 25 \\
\hline Lead resistance, $m \Omega$ & 120 & 20 & $<2$ \\
\hline Lead inductance, $\mathrm{nH}$ & 3 & 2 & $<0.2$ \\
\hline Interlead capacitance, fF & 25 & 3 & $<1$ \\
\hline Versatility & high & low & low \\
\hline Ease of inspection & high & high & low \\
\hline Ease of rework & difficult & semi-routine & difficult \\
\hline $\begin{array}{l}\text { Scale for economic } \\
\text { production }\end{array}$ & low & high & medium \\
\hline
\end{tabular}

the intermetallic precipitate to coarsen. Several goldbased precipitation hardening alloys are known and their aging response has been characterised $[6,7,8]$.

Another type of second phase strengthening mechanism involves the addition of a phase that has a low solubility in the matrix alloy at all temperatures. Because the dispersed phase is stable, the strengthening effect is much more resistant to heating. This type of dispersed phase provides strengthening in much the same manner as an intermetallic precipitate. Accordingly, a comparable particle size and volumetric density are required to obtain peak strength. This is difficult to achieve in practice so that dispersion strengthened alloys tend to have only moderately enhanced strength, although this is thermally stable. Such an alloy will normally be prepared containing a small fraction of a highly reactive constituent. For example, zirconium is used in the preparation of the well known zirconia grain stabilised (ZGS) platinum and goldplatinum alloys $[9,10]$. During heat-treatment of a homogeneous alloy of this type, conditions can be established where oxygen is able to diffuse into the parent material more rapidly than the strengthening 
element is able to diffuse to the surface. This can result in a fine internal dispersion of stable oxide particles. Once formed they are stable because zirconia is insoluble in platinum.

Metals may also be strengthened by the deliberate mixing in of much larger (0.1 to $100 \mu \mathrm{m}$ diameter), insoluble, particles and these are generally referred to as metal matrix composite materials (MMCs), The strengthening mechanism in this case is different and, in any case, is not applicable to fine bond wire, which can have a diameter of as little as $4 \mu \mathrm{m}$ for microwave applications.

The attainment of dispersion strengthened high gold alloys of bulk geometry by internal reaction at elevated temperature is not likely to be viable because oxygen and other constituents of the atmosphere are not soluble to any appreciable extent in gold [11]. This appeared to leave precipitation strengthening as the only foreseeable means for producing high strength gold- based bond wire.

\section{PRECIPITATION STRENGTHENED HIGH-GOLD JEWELLERY ALLOY}

In 1988, the development of a new gold alloy, of composition $\mathrm{Au}-1 \mathrm{wt} . \% \mathrm{Ti}$, for high carat jewellery applications was reported [12]. This alloy with a 990 millesimal fineness (i.e. $99.0 \%$ gold) can be endowed with the mechanical properties of a 9 carat alloy while retaining the hue and surface brilliance of 24 carat gold [13]. These improved

Figure 7

Added value of gold alloy bond wire in terms of a mark-up on the gold price, as a function of wire diameter. The increasing price premium of wire of reduced diameter reflects the escalating processing effort needed characteristics are obtained via a precipitation strengthening mechanism $[13,14,15,16]$.

The hardening characteristics of this precipitation strengthened alloy in bulk form are well established and are indicated in Figure 9. The curves represented indicate that the alloy has an exceptionally high resistance to over-aging at temperatures below $400^{\circ} \mathrm{C}$. This property, in particular, suggested that the Au- 1 wt. \% Ti alloy would be a promising candidate for an improved bond wire. Furthermore, the high gold content of the alloy made it likely that wire produced from it would match conventional gold alloy bond wire in its functional characteristics. Accordingly, it was decided to carry out a detailed evaluation of the Au-1wt.\% Ti alloy as fine wire.

\section{FINE WIRE OF THE Au-Iwt.\%Ti ALLOY}

A $1 \mathrm{~mm}$ diameter rod of the Au-1wt.\%Ti alloy, supplied to the jewellery specification, was heattreated at $800^{\circ} \mathrm{C}$ for one hour in high vacuum, to place the titanium in solid solution. It was then water quenched, and cold-drawn to $25 \mu \mathrm{m}$ diameter in 20 stages. No intermediate annealing treatments were used as these would have initiated the precipitation process. 


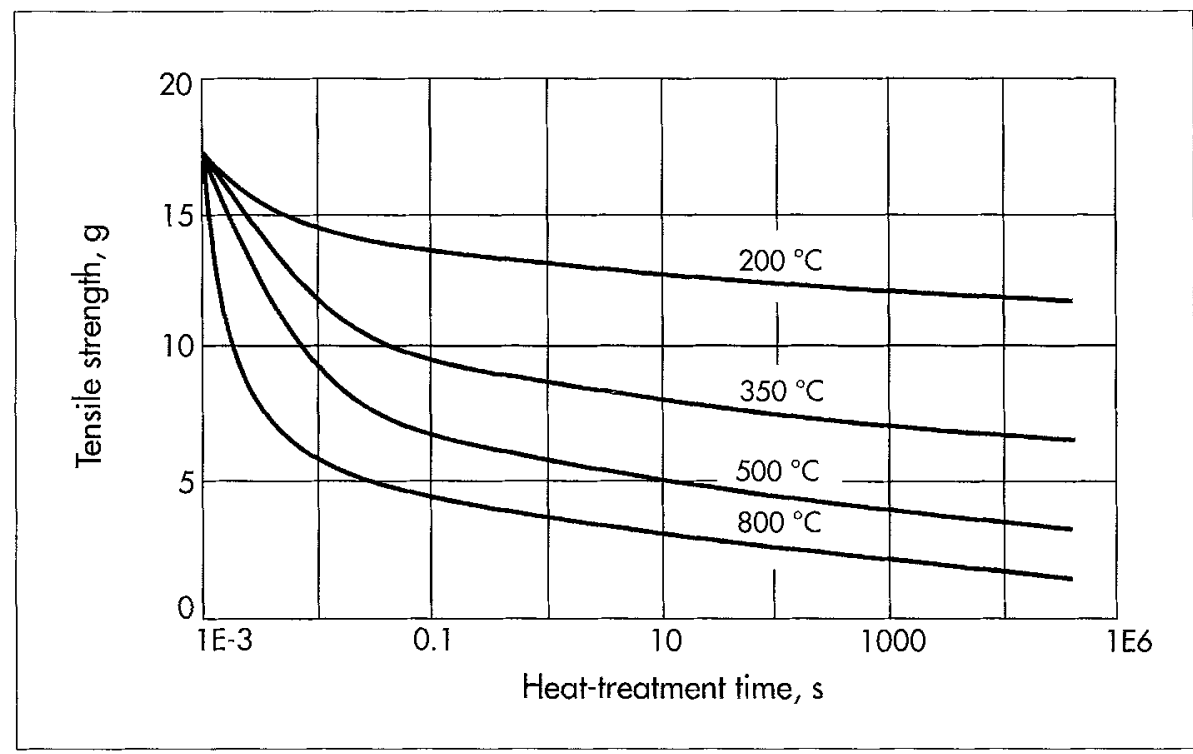

Figure 8

Annealing characteristics of doped gold bond wire alloys. The short heating times were achieved using an electrical pulse beating method

presented in Figure 10, obtained at room temperature and $400{ }^{\circ} \mathrm{C}$. The heat-treatment required to produce the maximum strengthening effect is governed by the the temperature and time of the process.

By contrast, a conventional gold alloy for bond wire requires upwards of 120 drawing stages and several intermediate anneals to prevent breakage, emphasising that the Au-1wt.\% Ti wire possesses a superior resistance to necking and consequential fracture.

Samples of the fine wire were heat-treated in air at a range of temperatures between 25 and $400{ }^{\circ} \mathrm{C}$ to induce precipitation strengthening. Strength data obtained from these samples revealed the following distinctive features:

a) At high and low precipitation treatment temperatures, the wire exhibits classical precipitation strengthening behaviour as shown by the data
These two parameters are functionally related, as shown in Figure 11. It can be seen from this graph that the heat-treatment temperature required to obtain peak strength is proportional to the logarithm of time, for both $25 \mu \mathrm{m}$ and $1 \mathrm{~mm}$ diameter wire. The similarity in the relationships for the two wire diameters indicates that the same strengthening mechanism is operative for both. Because it has been established that precipitation strengthening accounts for the mechanical properties of $1 \mathrm{~mm}$ diameter wire, this same mechanism must also be responsible for the strengthening of $25 \mu \mathrm{m}$ diameter wire. The offset with respect to time of the precipitation strengthening data for the Au-1wt.\%Ti alloy as fine

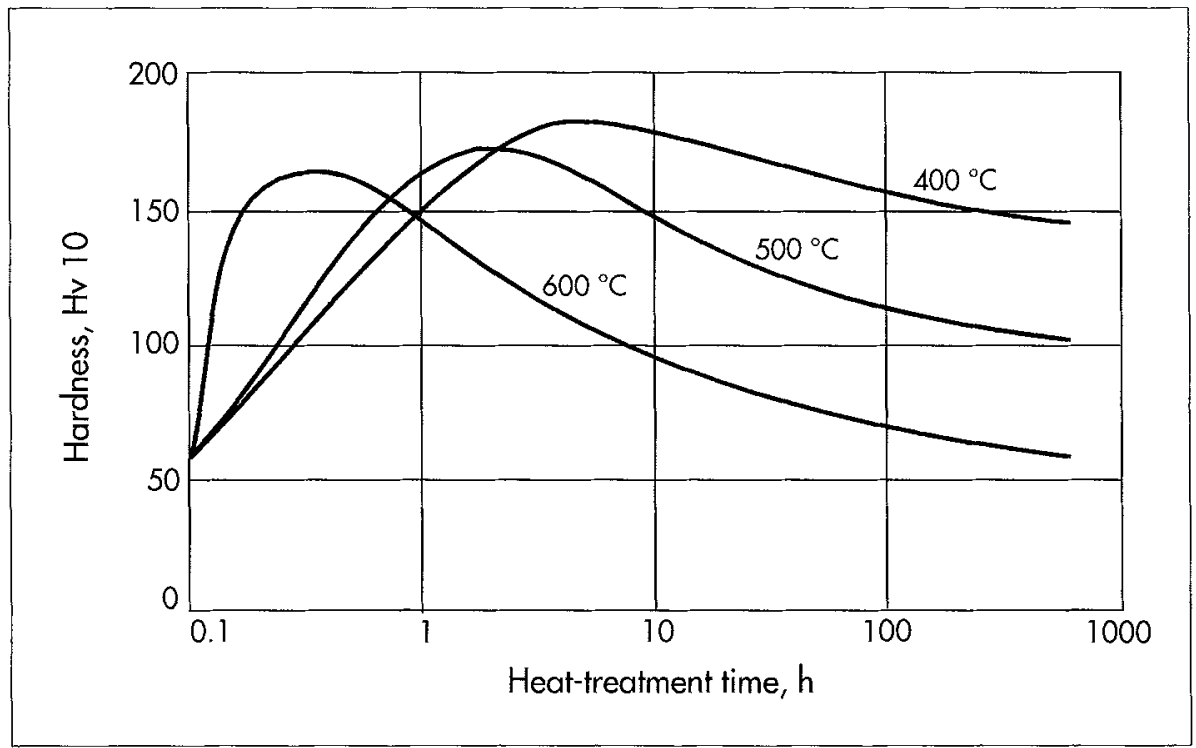

Figure 9

Precipitation hardening characteristics of the Au-1wt.\% Ti alloy, in bulk form, on heat-treatment at 600,500 and $400^{\circ} \mathrm{C}$.

Prior to the aging treatment, the material was solution-treated by heating at $800^{\circ} \mathrm{C}$, in high vacuum, for one hour and water quenched to room temperature 
Figure 10

Precipitation strengthening characteristics of the Au-1wt.\%Ti alloy, in the form of a $25 \mu \mathrm{m}$ diameter wire, at $400^{\circ} \mathrm{C}, 200^{\circ} \mathrm{C}$ and room temperature.

Classical precipitation hardening behaviour is exhibited on aging at $400^{\circ} \mathrm{C}$ and room temperature, but the sample of fine wire aged at $200^{\circ} \mathrm{C}$ shows a lower peak strength and minimal tendency to over-age

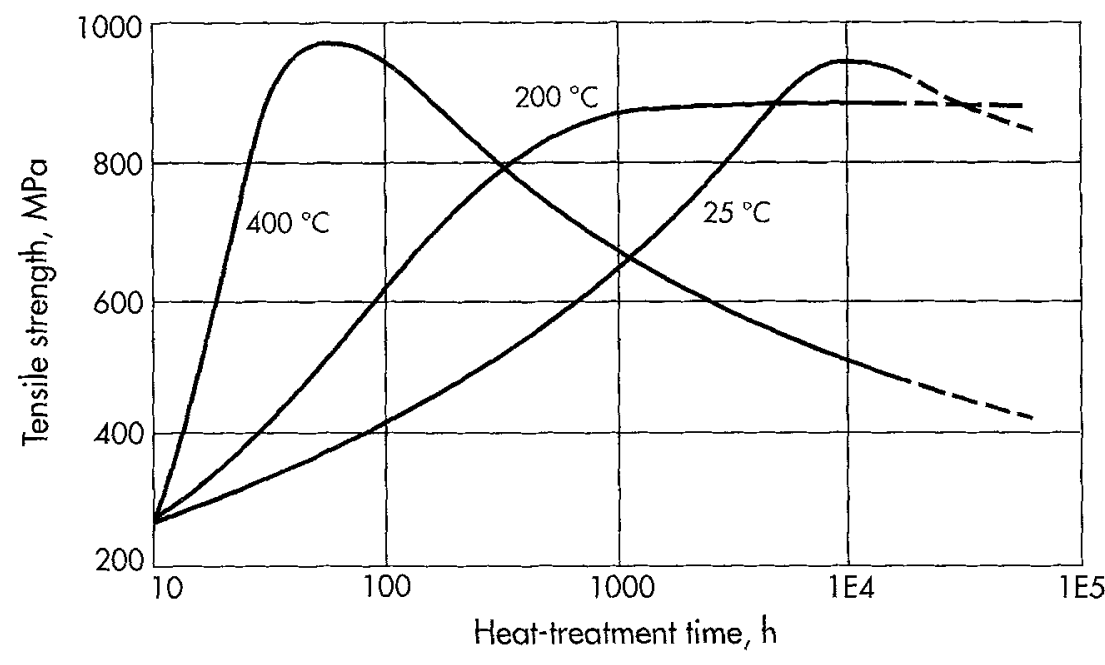

wire, compared to that for the thicker wire, can be ascribed to the annealing out of dislocations and point defects which are extensive in the heavily worked fine wire. These annealing processes have lower activation energies than that required to initiate precipitation strengthening. Hence, during the heat-treatment, these processes occur first and there is a delay before precipitation strengthening commences in the $25 \mu \mathrm{m}$ wire.

b) Heat treatment at $400^{\circ} \mathrm{C}$ and above results in the strength of the wire increasing to a peak of $1000 \mathrm{MPa}$, followed by a decline through overaging. This compares with a typical peak value of $275 \mathrm{MPa}$ for conventional gold bond wire of $25 \mu \mathrm{m}$ diameter.

Figure 11

The relationship between aging heat-treatment time and temperature to achieve peak tensile strength in the Au-1wt.\% Ti alloy when in the form of $25 \mu \mathrm{m}$ and $1 \mathrm{~mm}$ diameter wires c) At temperatures below $400{ }^{\circ} \mathrm{C}$ but above about $100^{\circ} \mathrm{C}$, there is a similar enhancement of strength but no over-aging is observed. This behaviour is consistent with dispersion strengthening, as described above. The dispersed phase in this case is likely to be an oxide of titanium. The formation of such compounds by reaction with the atmosphere is possible because the maximum distance the oxygen has to diffuse to reach the centre of the fine wire is only $13 \mu \mathrm{m}$. This could account for dispersion strengthening occurring in fine wire of the alloy while it is largely absent in thicker forms of the material. The transition to regular precipita- 
tion strengthening above $400{ }^{\circ} \mathrm{C}$ must therefore mark the point at which the rate of precipitation of the intermetallic phase overtakes that at which the minority phase within the alloy is able to react with the atmosphere.

d) When the wire is left in an ambient environment, it again precípitation strengthens and over-ages in the classical manner. One possible explanation for this phenomenon, which is not observed in bulk alloys at ambient temperatures, is that precipitation is occurring under the driving force of the stored energy imparted to the material on cold working to fine wire. This explanation is consistent with the observation that pure gold (>99.999\% purity), when subjected to heavy mechanical cold work, recovers and recrystallises during storage at room temperature [17]. At ambient temperature, there is insufficient activation for the development of a dispersed refractory phase by reaction with the atmosphere. formed. A reel of wire of the Au-1wt.\%Ti alloy was prepared as described in the previous section. After being drawn down to $25 \mu \mathrm{m}$, the wire was cut in two and one of the two equal lengths was again solutiontreated, quench-cooled and then aged in an ambient atmosphere, while the other half was similarly processed but in high vacuum throughout. The results are summarised in Table 2 (page 142) and the aging curves given in Figure 12.

The second solution-treatment that was provided removed the work hardening produced by the cold drawing to fine wire, thereby reducing the tensile strength of the wire. The strength of the wire that had been heat-treated in high vacuum decreased from $275 \mathrm{MPa}$ to $90 \mathrm{MPa}$, which is close to the tensile strength of annealed gold. On the other hand, the wire exposed to the ambient environment did not soften to the same extent, with its strength decreasing to $175 \mathrm{MPa}$. By implication, there must be some type of mechanism acting that either prevents the alloy from annealing completely or provides some strengthening.

On aging at $350^{\circ} \mathrm{C}$, in their respective environments, the two wire samples behaved in a totally dif-

\section{TESTS FOR DISPERSION STRENGTHENING IN FINE WIRE}

The conformance of the heat treatment data on fine wire to classical precipitation strengthening behaviour in the high and ambient temperature regimes is sufficiently convincing to provide confidence about the interpretation. On the other hand, the assumption that dispersion strengthening occurred in the intermediate temperature range was not as well supported and so there was need to obtain some additional evidence. For this purpose, the following experiment was per-

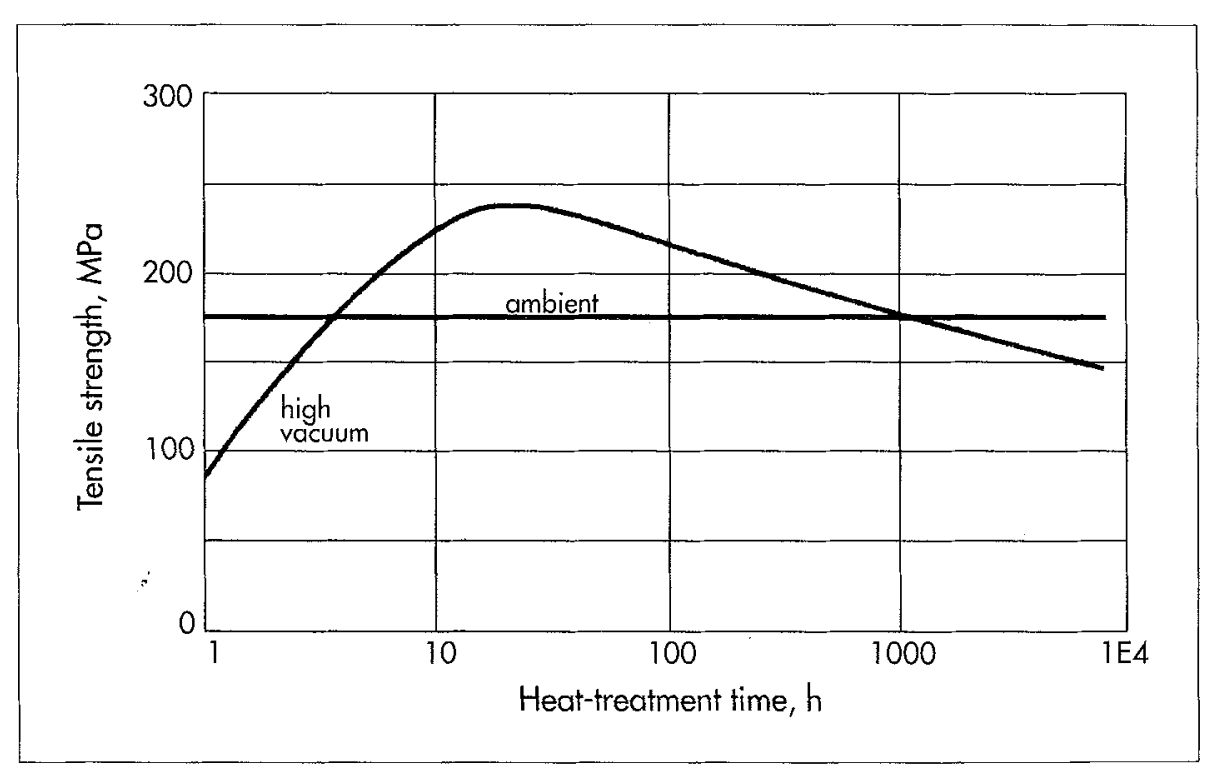

Figure 12

Precipitation strengthening characteristics of $25 \mu \mathrm{m}$ diameter wire of the Au-1wt.\% Ti alloy, at $350^{\circ} \mathrm{C}$, in high vacuum and in air.

Prior to the aging treatment, the two samples of wire were solution-treated, at $800^{\circ} \mathrm{C}$, for one hour, in high vacuum and in air respectively, followed by a water quench 
Figure 13

Failure load of $25 \mu \mathrm{m}$ diameter wire of half-hard pure gold and of the new Au-1wt.\%Ti, goldclad, bond wire as a function of heat-treatment time at $400^{\circ} \mathrm{C}$.

Conventional gold bond wire rapidly softens in response to the heat-treatments associated with semiconductor device packaging

and use, while the new bond wire is clearly more resisistant to such treatment. The initial drop in strength of the new bond wire on heat-treatment is due to annealing of its gold cladding

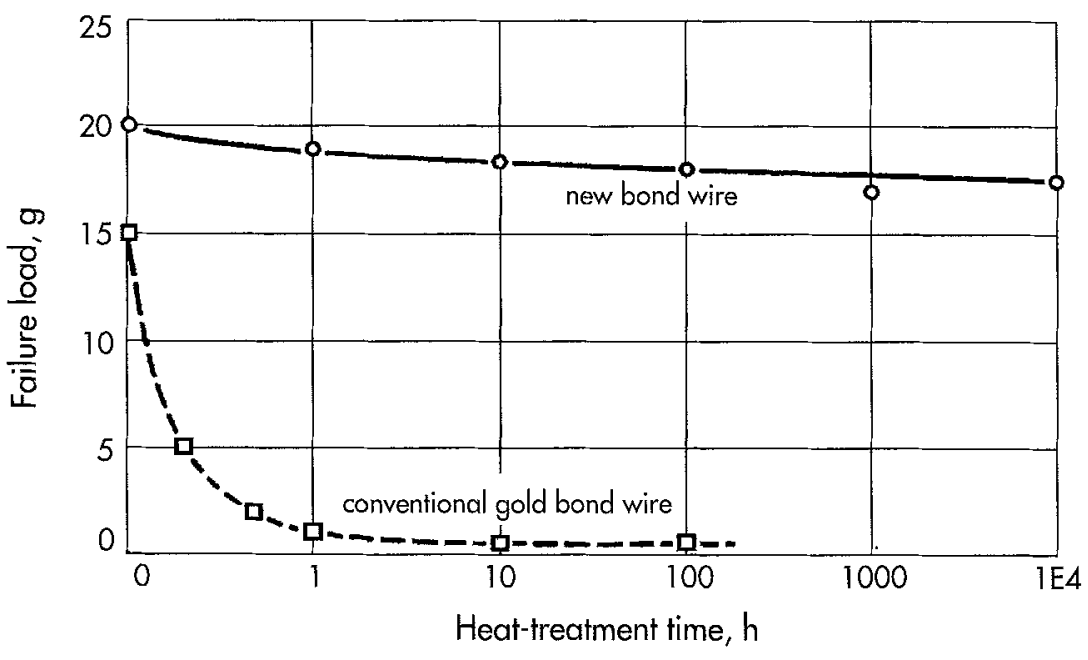

ferent manner. The tensile strength of the wire that had been aged in high vacuum increased three-fold to a peak of $240 \mathrm{MPa}$, after about $15 \mathrm{~h}$ heat treatment, and then declined. This response was entirely characteristic of a precipitation-strengthened material and the three-fold strength enhancement was similar to that measured for the alloy in bulk form (see Figure 9, page 139). Furthermore, the $15 \mathrm{~h}$ of heat-treatment required to reach peak strength is in close agreement with the duration predicted from Figure 11 (page 140) for $1 \mathrm{~mm}$ diameter wire. As indicated in Figure 12 , the wire that was exposed to air throughout the

Table 2

Tensile strength of $25 \mu \mathrm{m}$ diameter wire of the Au-1wt.\% Ti alloy following beat-treatment in air and high vacuum

Tensile strength, MPa, in:

Ambient

Sequential

processing steps

$\begin{array}{lcc}\text { a) as drawn } & 275 & 275 \\ \text { b) } 800^{\circ} \mathrm{C} \text {, for I h, } & 90 & 175 \\ \text { quench cooled } & 240 & 175 \\ \text { c) } 350^{\circ} \mathrm{C} \text {, for } 15 \mathrm{~h} & 80 & 175 \\ \text { d) } 350^{\circ} \mathrm{C} \text {, for } 5000 \mathrm{~h} & & \end{array}$

solution and aging treatments was essentially unaffected by the heat-treatment even after $5,000 \mathrm{~h}$ at $350^{\circ} \mathrm{C}$. The stability of the mechanical properties of the wire at this temperature suggests that the processing that it had received had endowed it with dispersion strengthening.

The ability to dispersion harden a Au-1wt.\% Ti alloy would appear to fly in the face of the fact that oxygen has an extremely low solubility in gold. However it is known that small additions of iron and tin significantly enhance the diffusion of oxygen into gold alloys, which occurs along grain boundaries [18]. The high defect density present in the gold-titanium alloy matrix, when cold-worked to fine bond wire, might therefore provide a route for oxygen diffusion. The diffused-in oxygen can then react with the titanium inside the alloy to form a distribution of fine oxide particles. In the gold-rich alloys containing small amounts of iron and tin, the distance that the oxygen diffused in was restricted to about $10 \mu \mathrm{m}$, which is consistent with dispersion strengthening of the Au-1wt.\%Ti alloy only being evident in fine wire of this material. Furthermore, dispersion strengthened gold-titanium alloys containing low concentrations of ti- 
tanium ( 0.04 to $0.08 \%$ ) have been prepared by spraying the molten metal into air [19]. It is a prerequsite of this process that the spray is in the form of fine droplets, less than $5 \mu \mathrm{m}$ diameter, in order to oxidise all of the titanium in the short time that the alloy is hot.

Having established that strengthening of a Au1wt.\%Ti fine wire can be achieved by either the pre-

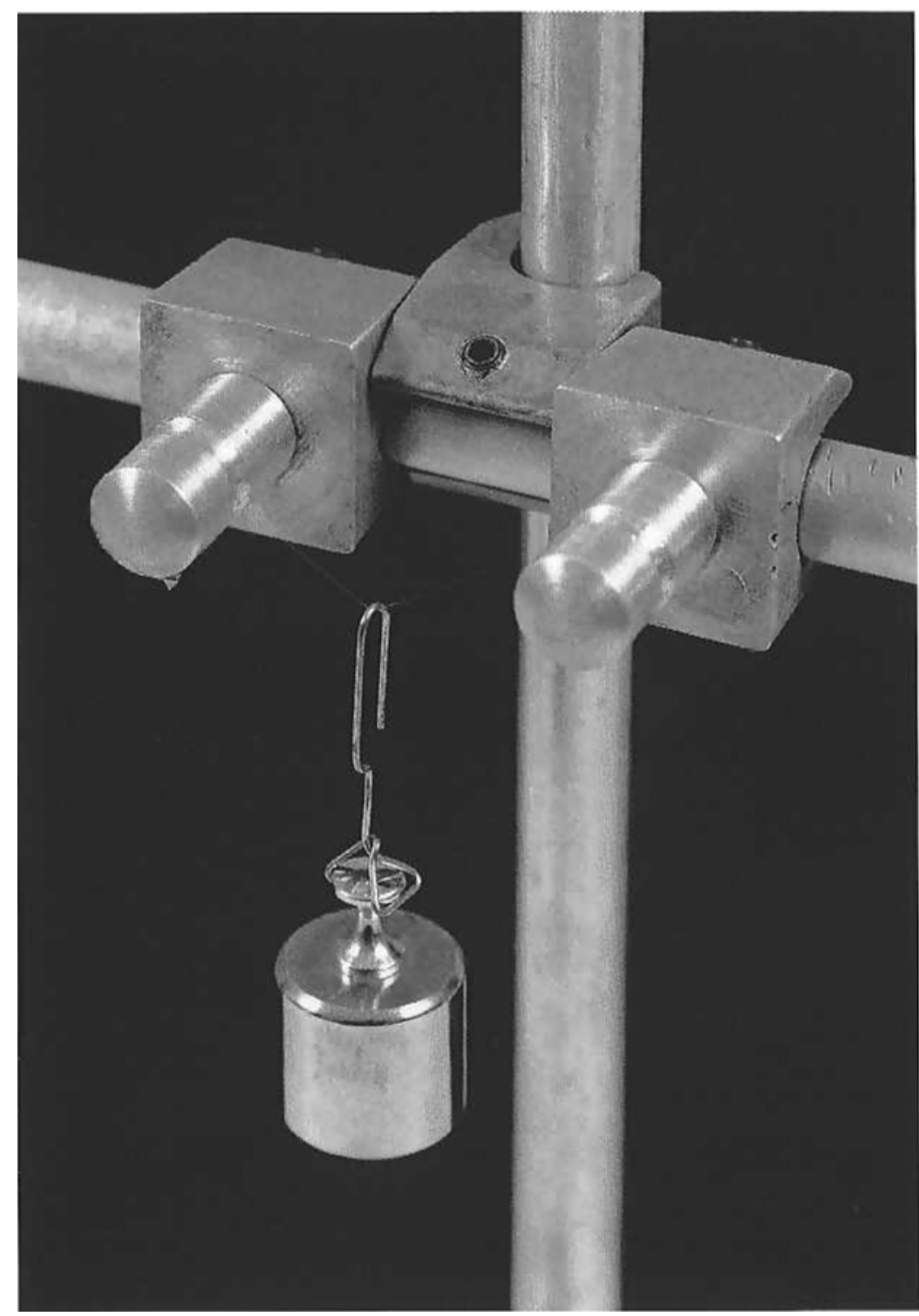

Figure 14

A thermomechanically strengthened wire of the Au-1wt.\%Ti alloy,

$25 \mu \mathrm{m}$ in diameter, supporting a weight of $50 \mathrm{~g}$.

Medsurements of the tensile strength of this wire indicate that it could in principle support a load of $150 \mathrm{~g}$ cipitation of a finely divided intermetallic phase or the formation of a dispersed refractory phase, or by a combination of both types of inclusion, the appropriate processing conditions for achieving particular strengthening characteristics were established by experiment. Under a particular regime of thermomechanical treatment it was found possible to selectively develop the dispersed refractory phase in the fine wire and thereby prevent loss of strength by over-aging.

A fabrication route was devised that yielded fine wire with a tensile strength close to $400 \mathrm{MPa}$, which remained stable at this value even after being held for $10,000 \mathrm{~h}$ (one year) at $400^{\circ} \mathrm{C}$ and more than $1,000 \mathrm{~h}$ at $600^{\circ} \mathrm{C}$ [20]. This contrasts with the rapid decline in mechanical properties of a conventional gold bond wire, subject to the same heating regime, as shown in Figure 13.

The high strength that can be developed in the Au-1wt.\% Ti alloy by a suitably optimised thermomechanical treatment is demonstrated in Figure 14, which shows a $25 \mu \mathrm{m}$ diameter wire supporting a $50 \mathrm{~g}$ weight, following its heattreatment in air at $400^{\circ} \mathrm{C}$ for a year. This wire was fabricated with a remarkable tensile strength of $1540 \mathrm{MPa}$ and an elongation to failure of $6 \%$. The attained strength is equivalent to that of piano wire, when scaled to $25 \mu \mathrm{m}$ diameter. By contrast, pure gold wire would be incapable of supporting even the paper clip shown after being subjected to an identical heat treatment!

Wire of this strength is not desirable for bond wire because it possesses excessive stiffness and hardness for interconnection of semiconductor devices but could find application in woven decorative products, as the $25 \mu \mathrm{m}$ wire is actually finer than a cotton thread. Figure 15 shows a woven multistrand tube made with $100 \mu \mathrm{m}$ diameter wire of the Au1wt.\% Ti alloy. 


\section{SEMICONDUCTOR INTERCONNECTION USING THE NEW BOND WIRE}

Preliminary trials have been made using the new high strength bond wire for making interconnects to semiconductor devices. Bonds to aluminium and gold pads have been successfully made using the wire on conventional wire bonding machines, although the machine settings needed to be slightly altered in order to obtain satisfactory microwelds. However, by applying a cladding of pure gold to the wire, the Au-1wt.\% Ti alloy is made virtually indistinguishable from conventional dilute gold alloy bond wire in both its electrical properties and bonding characteristics. The latter embraced thermocompression wedge-wedge, thermosonic wedge-wedge and thermosonic ball-wedge welds. Despite the enhanced tensile strength of this wire, the hardness of the clad wire is comparable to that of the conventional product, making it suitable for interconnects to the relatively delicate integrated circuits of gallium-arsenide. These chips are capable of operating at higher temperatures than those of silicon and the benefits of providing them with interconnects that are mechanically stable at elevated temperatures are obvious.

\section{CONCLUSIONS}

The Au-1wt.\%Ti alloy can be substantially strengthened by a fine dispersion of two types of second phase particles. The alloy in bulk form can be reinforced by particles of an intermetallic phase that precipitates in response to a suitable heat treatment. When prepared in the form of a fine wire, less than $100 \mu \mathrm{m}$ diameter, it can also be strengthened through the formation of a dispersed refractory phase in response to heating in an ambient atmosphere. Thereby, fine wire can be made stable to extended heat treatment at elevated temperature. Other characteristics of this material, namely its

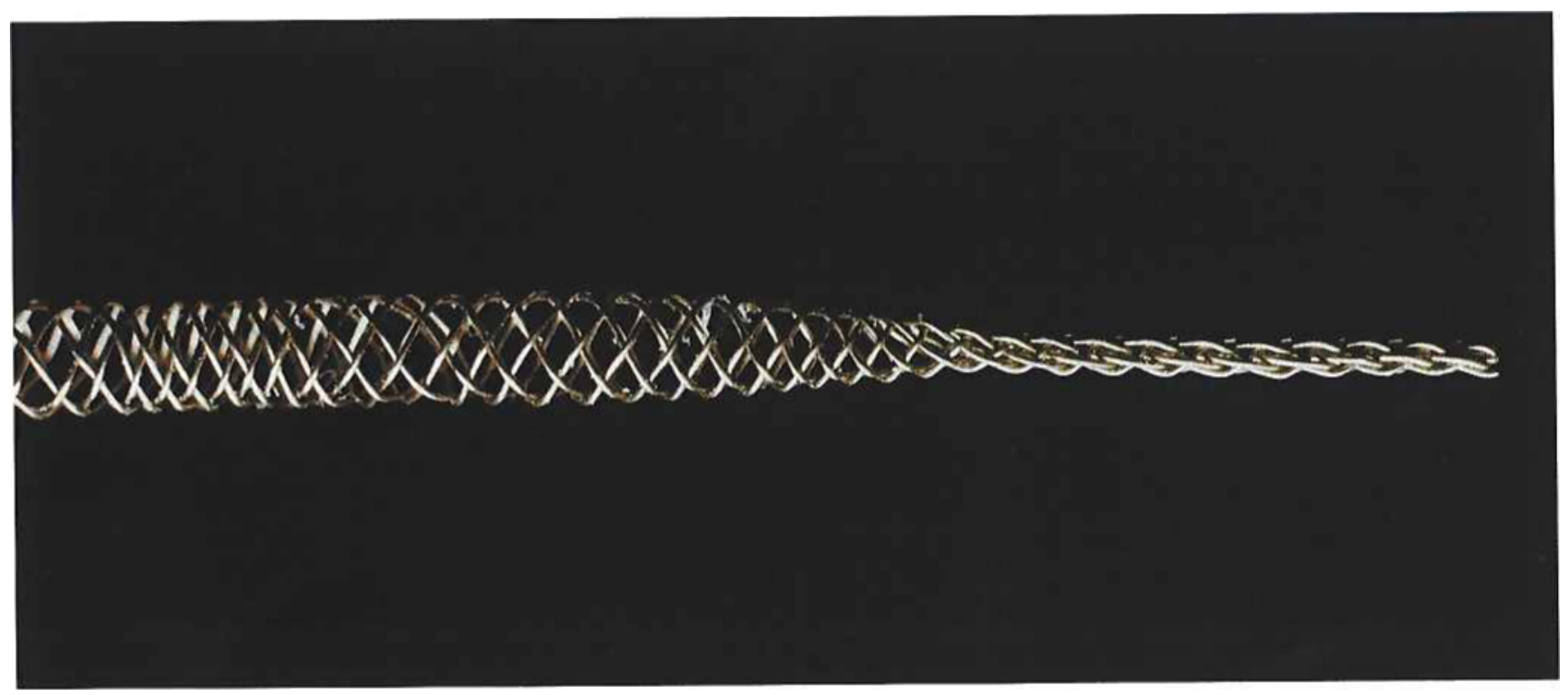

Figure 15

An 8-strand braid made with $100 \mu$ m diameter wire of the Au-1wt.\% Ti alloy:

The sample demonstrates the ability to produce coreless open basket braid with full control of the pitch and

diameter of the braid, using fine wire of this alloy. Conventional braided products

usually comprise 16 or more strands and can therefore be made correspondingly more elaborate.

The braiding trial was carried out by G. Cooke of J.R. Cooke and Sons, Wotton-under-Edge, Gloucestershire 
conductivity and weldability, are closely similar to those of conventional dilute gold alloys used for bond wire. The beneficial properties of fine wire of the Au-1wt.\%Ti alloy are currently being exploited in interconnects for new generation semiconductor devices, and in particular for micron valves.

\section{ACKNOWLEDGEMENTS}

The World Gold Council and GEC-Marconi Limited are acknowedged for supporting the work. The contribution of the World Gold Council in supplying samples of the Au-1wt.\% Ti alloy is also gratefully acknowledged. Mr. G. Cooke of J. R. Cooke and Sons produced the braided tube shown in Figure 14 (page 143).

\section{REFERENCES}

1. S. Prasad \& A. Saboui, 'An improved wire bond pull test', Solid State Technology, 1991, 34(6), 39-41

2. R. Bidin, 'High pin count wirebonding: The challenge for packaging, Solid State Technology, 1992, 35(5), 75-77

3. 'Gold 1991', Gold Fields Mineral Services Ltd., London, 1991

4. N.A. Cade \& R.A. Lee, 'Vacuum microelectronics', GEC Journal of Research, 1990, 7(3), 129-138

5. S. Tomiyama \& Y. Fukui, 'Gold bonding wire for semiconductor applications', Gold Bull., 1982, 15(2), $43-50$
6. H. Izumi, M. Bapna E.H. Greener \& M. Meshii, 'Precipitation hardening in gold-based iron alloys', Proc. Conf., Sixth International Congress for Electron Microscopy, 1966, Kyoto, 395-396

7. E. Raub \& M. Engel, 'The alloys of zirconium with copper, silver and gold', Z. Metallkunde, 1948, 39(6), $172-177$

8. M. Graham, 'Precipitation hardening in gold-titanium alloys', Proc. Conf. Thirty-first Annual Meeting of the Electron Microscopy Sociery of America, 1973, New Orleans, 148-149

9. G.L. Selman, J.G. Day \& A.A. Bourne, 'Dispersion strengthened platinum', Platinum Metals Review, 1974, $18(2), 46-56$

10. A.E. Heywood \& R.A. Benedek, 'Dispersion strengthened gold-platinum', Platinum Metals Review, 1982, 26(3), 98-104

11. M. Poniatowski \& M. Clasing, 'Dispersion hardened gold: A new material of improved strength at high temperatures', Gold Bull., 1972, 5(2), 34-36

12. A.M. Tasker, 'The promise of 990 gold', Aurum, 1988, 34(Summer), 62-67

13. G. Gafner, 'The development of 990 gold-titanium: Its production, use and properties', Gold Bull., 1989, 22(4), 112-122

14. M.E. Graham, 'Precipitaion strengthening of an Au4at.\%Ti alloy', Ph.D. Thesis, North Western University, Evanston, Illinois, USA, 1974

15. D.P. van Heerden et al., 'Precipitation in rapidly solidified Au-Ti alloys', Matenals Letters, 1991, 10(9), 425430

16. '990 gold', Gold Technology, 1992, 6(5), 1-12 (four articles, entire issue)

17. H. Ramsey, 'Metallurgical behaviour of gold wire in thermal compression bonding', Solid State Technology, $1973,16(10), 43-47$

18. H. Ohno \& Y. Kanzawa, 'Internal oxidation in gold alloys containing small amounts of Fe and Sn', J. Materials Science, 1983, 18(3) „919-929

19. A.S. Darling, 'Improvements in and relating to the dispersion strengthening of metals', United Kingdom Patent No. 1280 815, filed 14 July 1969

20. G. Humpston \& D.M. Jacobson, 'Methods of making electrical conductors', United Kingdom Patent Application No. 2235211. United States Patent No 5073210, European Patent Application No 90305266.0 